\title{
Recycling of In-site waste soil material to fill a hollow between PHC pile and Earthen wall
}

\author{
Jang, Myung-Houn Choi, Hee-Bok ${ }^{*}$ \\ Department of Architectural Engineering, Jeju National University, Jeju-si, Jeju-do, Korea
}

\begin{abstract}
This study evaluated the recycling potential of in-site waste soil as pile back filling material (PBFM). We performed experiments to check workability, segregation resistance, bond strength, direct shear stress test, and dynamic load test using in-site waste soil in coastal areas.We found that PBFM showed better performance than general cement paste in terms of workability, segregation resistance, and bond strength. On the other hand, the structural performance of PBFM was slightly lower than that of general cement paste due to the skin friction force of pile by Pile Driving Analyzer and direct shear stress. However, because this type of performance degradation in terms of structure can be improved through the use of piles with larger diameter or by changing the type of pile, considering the economics and environment, we considered that recycling of PBFM has sufficient value.
\end{abstract}

Keywords : in-site waste soil, construction waste, recycling, pile back filling material, solidification agent

\section{Introduction}

\subsection{Research background and objective}

Piling hammer practice and pre-board piling practice are the basic techniques used for pile work. Recently, pre-board piling practice has been used more frequently to reduce the civil claims caused by noise and vibration. In addition, as many of the recent large-scale construction projects in Korea have been conducted at landfills, coastal areas and the four major river basins, where the foundation of ground is usually soft, a lot of in-site waste soil is generated when drilling for the installation of augured piles.

In-site waste soil is unavoidable when using pre-board piling practice, which brings about an

Received : February 22, 2012

Revision received : July 10, 2012

Accepted : July 27, 2012

* Corresponding author : Choi, Hee-Bok

[Tel: 82-64-754-3731, E-mail: chb0319@jejunu.ac.kr]

(C) 2012 The Korea Institute of Building Construction, All rights reserved. increase in construction cost (transportation cost) for carrying out in-site waste soil, as well as the material cost of cement paste to be injected on the skin to fix the piles.

Some of the high quality in-site soil of generated at construction sites is recycled for soil compaction to place lean concrete, but in-site waste soil that contains mud cannot be recycled, and must be disposed of as construction waste, which also brings about an increase in construction cost. Although some is used as dredged soil, it poses environmental risks such as soil pollution. Technologies that utilize in-site soil have recently been developed[1,2], but are limited to the application of in-site soil for backfilling material for underground piles or hollow parts under a road.

Therefore, this study aims to develop a technology for recycling in-site soil as a replacement for cement paste injected on the skin of piles to reduce the disposal cost of in-site waste soil and to protect the environment. 


\subsection{Research scope and method}

As the size and number of PHC auger drilled piles are determined by support (shear strength and skin friction of piles), for PHC auger drilled piles the material filling between the drilling hole and pile serves as filling material for self support of the piles at the early phase of loading, and provides skin friction upon loading.

As mentioned earlier, the in-site soil used in this study was obtained from D construction site in the coastal area in Busan, and the in-site soil material contains of a large amount of mud, as shown in Figure 1.

To determine whether the in-site soil with mud can be used as a filling material for void space between PHC piles and earthen wall, segregation resistance, compressive strength, bond strength and shear strength were evaluated based on which dynamic load tests were performed at the construction site. Through the tests, the applicability of in-site soil as a filling material in place of the cement paste currently in wide use was evaluated.

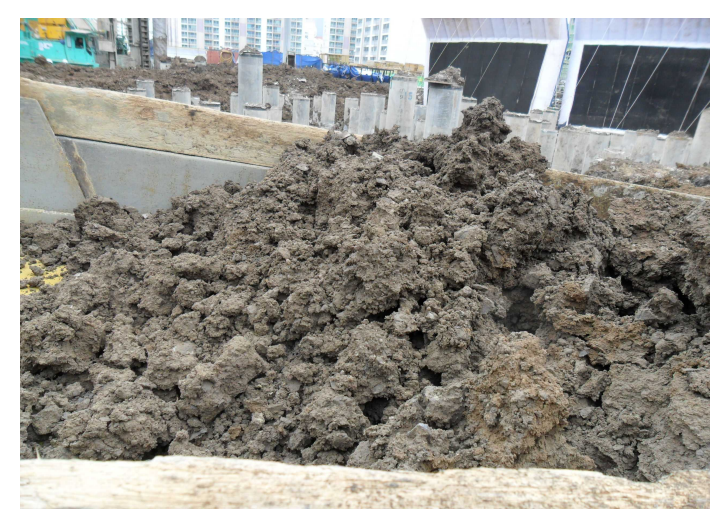

Figure 1. Soil in coastal area

\section{Experiment plan and method}

\subsection{Experiment plan}

The filling material for PHC auger drilled piles used in this study is used as a pile backfilling material (PBFM) in place of the cement paste in wide use. Tables 1 and 2 indicate the items to be tested and mix proportion to evaluate the applicability of in-site soil.

The mix proportion of cement paste was determined in compliance with the Guide Specification of Korea Land and Housing Corporation and the Guide Specification 30535[3] for housing construction. $1.16 \mathrm{~kg}$ of solidifying agent per $1 \mathrm{~m}^{3}$ of water was added in the mix proportion of PBRM, taking solubility of the solidifying agent into account.

Table 1. Experiment plan

\begin{tabular}{cc}
\hline Evaluation contents & Evaluation method \\
\hline Workability & Right after mix \\
\hline Segregation resistance & 3hours and 24 hours after mix \\
\hline Compressive strength & 7days, 14days and 28days \\
\hline Bond strength & 14days \\
\hline Direct shear test & 14days \\
\hline Dynamic load tests & on the day and 7days
\end{tabular}

Table 2. Mix proportion

\begin{tabular}{cccccc}
\hline $\begin{array}{c}\text { Type of } \\
\text { backfilling } \\
\text { material }\end{array}$ & W/C & C & W & Soil & $\begin{array}{c}\text { Solidification } \\
\text { agent }\end{array}$ \\
\hline PBFM & $250 \%$ & $186.6 \mathrm{~kg}$ & $466.6 \mathrm{~kg}$ & $733.3 \mathrm{~kg}$ & $0.54 \mathrm{~kg}$ \\
\hline Cement Paste & $83 \%$ & $880 \mathrm{~kg}$ & $730 \mathrm{~kg}$ & - & - \\
\hline
\end{tabular}

The solidifying agent was manufactured to melt 1.16kg per 1000l, and for this reason the agent can be used at a certain proportion to water. Therefore, the mix proportion of PEFM is shown in Table 2, and the water to cement ratio was determined through a preliminary experiment to use the minimum volume of cement required to develop the required compressive strength $(5 \mathrm{MPa}$ at 28 days) and secure construct ability (slump flow; twice or larger than $80 \mathrm{~mm}$ in diameter).

\subsection{Materials}

Only the natural or wet in-site soil from which 
coarse soil was separated in wet condition was used; and the grading curve is different from the general one, and the filter should not be clogged in the separation process. Therefore, the cumulative percentage passing according to moisture content was evaluated rather than the grading curve of the in-site soil, and the results are illustrated in Figure 2.

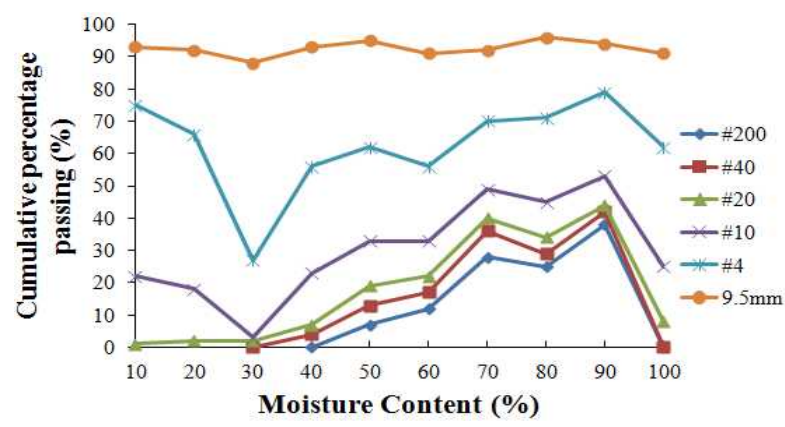

Figure 2. Cumulative percentage passing according to moisture content

It is found that there was no cumulative percentage when using a $9.5 \mathrm{~mm}$ sieve based on the specimen volume passing through a sieve, but there was a rapid decrease in cumulative percentage in Sieve \#4 at about 30\% moisture content. It is found that the soil was lumped at 20 30\% moisture content, and the sieve was clogged at $100 \%$ moisture content.

Therefore, core stone (small stone generated while drilling) was separated from the in-site soil used in the study by sifting the soil through Sieve \#4, and the natural state of in-site soil was used as shown in Figure 3.

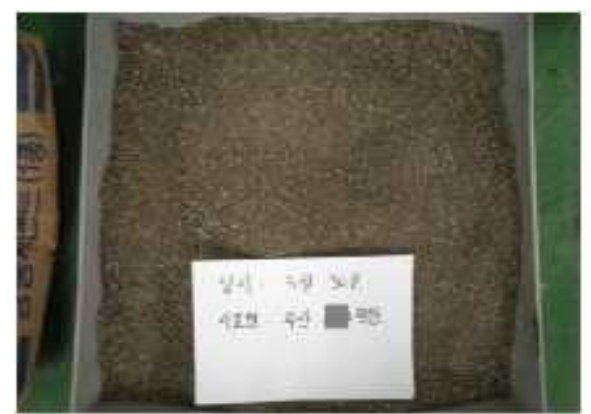

Figure 3. Soil passed a $5 \mathrm{~mm}$ sieve
In addition, the mud in the raw material of the specimen used in this study (in-site soil) could be mixed for the first short period of time due to its slight fluidity. The mud became hardened in the course of transportation and long-term exposure to the air. To take into account the characteristics of a construction site in the laboratory tests, the soil was crushed without separating the hardened mud and then was sifted through Sieve \#4(4.75mm) and mixed to use.

In the dynamic load tests at site, bond tests, and shear tests, PHC piles used at site was cut to manufacture the sample for the tests to reflect the actual conditions of a construction site. The dimension of $\mathrm{PHC}$ pile is indicated in Table 3.

Table 3. Pile dimension

\begin{tabular}{cccccc}
\hline & Diameter & Thickness & $\begin{array}{c}\text { Cross } \\
\text { sectional area }\end{array}$ & Length & $\begin{array}{c}\text { Penetrated } \\
\text { depth }\end{array}$ \\
\hline PHC & $600 \mathrm{~mm}$ & $90 \mathrm{~mm}$ & $1441.99 \mathrm{~cm}^{2}$ & $15 \mathrm{~m}$ & $13 \mathrm{~m}$ \\
\hline
\end{tabular}

In addition, to secure the required strength of in-site soil a solidifying agent specially developed for this study was used. The solidifying agent is a powder form of inorganic chloride, composite consisting of metal elements and inorganic alkali metal including carbon groups and iron groups.

\subsection{Experiment method}

To understand the dynamic characteristics and performance of PBFM, fluidity was evaluated using a circular cylinder with dimension of $80 \mathrm{~mm}$ (diameter) $\times 80 \mathrm{~mm}$ (height) in compliance with ASTM D6103[4] . In terms of the segregation resistance, the bleeding level was measured at 3 hours and at 24 hours after placement, respectively, in compliance with ASTM C940[5]. The compressive strength was measured in compliance with KS F2405, and a total of 18 specimens (3 specimens of PBFM and of cement mortar for each test) were manufactured and 
measured at 7, 14 and 28 days.

For the bond strength test, part of PHC pile was cut as shown in Figure 4, and on this mould was made in the size of $50 \mathrm{~mm} \times 50 \mathrm{~mm} \times 50 \mathrm{~mm}$ and filled with PBFM and cement paste. A total of 6 specimens were manufactured (3 specimens of each material). The bonding strength was reached in an open construction site and measured at 14 days of curing. The displacement was controlled at $0.2 \mathrm{~mm} / \mathrm{min}$ using UTM.

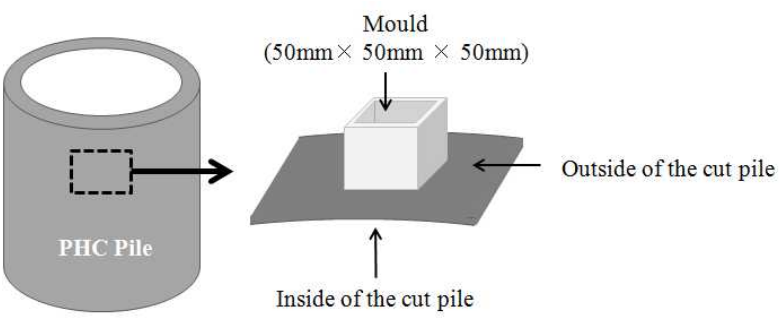

Figure 4. Specimen of bonding test

As shown in Figure 5, the direct shear test equipment consists of horizontal loading device, vertical loading device, LVDT and load cell. The horizontal loading device can be controllable at displacement velocity, the vertical loading device can put vertical stress, the LVDT can measure displacement in both horizontal and vertical directions, and load cell can measure the load put horizontally.

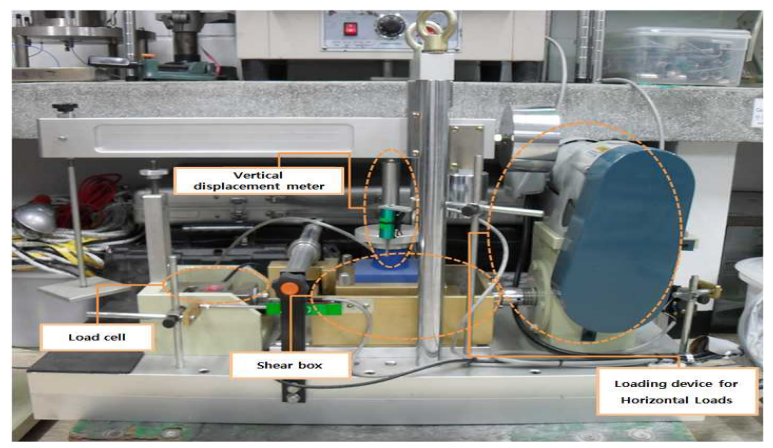

Figure 5. Direct shear test equipment

A mould for specimen manufacture was made, fitting to the shear box. The surface of concrete structure was formed first at $2 \mathrm{~mm}$ of thickness with the material identical to the existing piles. PBFM was placed on the top at $2 \mathrm{~cm}$ thickness, and measured at 14 days. To understand the effect of surcharge load (horizontal load at the pile), the test was performed by putting $0.5,1.0$, and $1.5 \mathrm{~kg} / \mathrm{cm}^{2}$ at the shear velocity of $1 \mathrm{~mm} / \mathrm{min}$. For the dynamic load test at site, the constant length and penetrated depth of PHC pile was applied as $15 \mathrm{~m}$ and $13 \mathrm{~m}$, respectively, considering the site condition and cost. Then, a comparative analysis of skin friction was conducted between cement paste and PBFM.

\section{Experiment results}

\subsection{Flowability}

The fluidity of PBFM was evaluated using a circular cylinder with a size of $80 \mathrm{~mm}$ (diameter)x $80 \mathrm{~mm}$ (height) as shown in Figure 6. According to ASTM D6103, for the filling material to be filled satisfactorily, the flow value should be twice as large as the diameter of the cylinder.
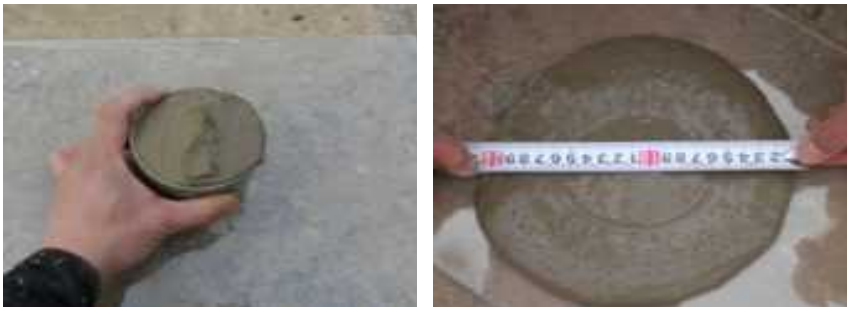

Figure 6 . Workability test

As illustrated in Figure 7, the flow value of PBFM was $197 \mathrm{~mm}$, which is 2.4 times larger than the cylinder diameter of $80 \mathrm{~mm}$. For cement paste, the cement was segregated from water due to its high water-to-cement ratio, and it was impossible to measure the flow value, on which basis it is believed that if applied at a construction site, a problem might arise related to filling ability. 


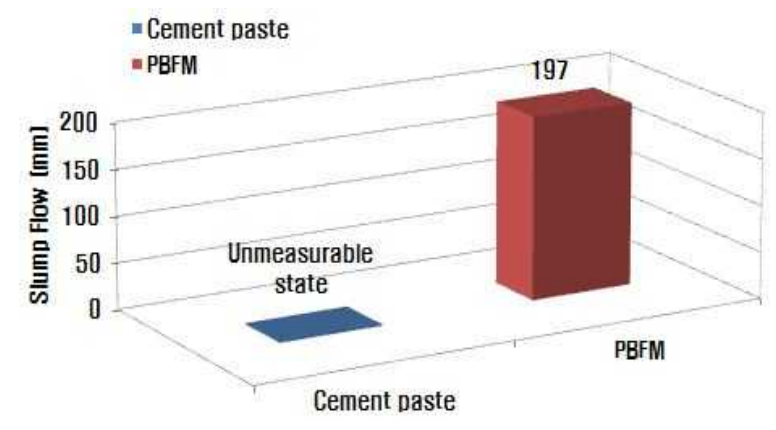

Figure 7 . Workability test results

\subsection{Segregation resistance}

According to fluidity evaluation in section 3.1, considerable segregation was found in cement paste. To check changes in segregation over time, segregation resistance was measured for the two specimens at 3 hours and 24 hours after mixing, respectively. As shown in Figure 8, 20ml of bleeding was found in cement paste 3 hours after mixing, while $100 \mathrm{ml}$ of bleeding was found in cement paste after 24 hours of mixing. On the other hand, no bleeding was found in PBFM. There was surplus water in the grout mass because too much water was mixed compared to the volume of cement. When the bleeding phenomena took place under the ground and excessive evaporation occurred, the properties of the ground would be changed, which would affect skin friction of piles.

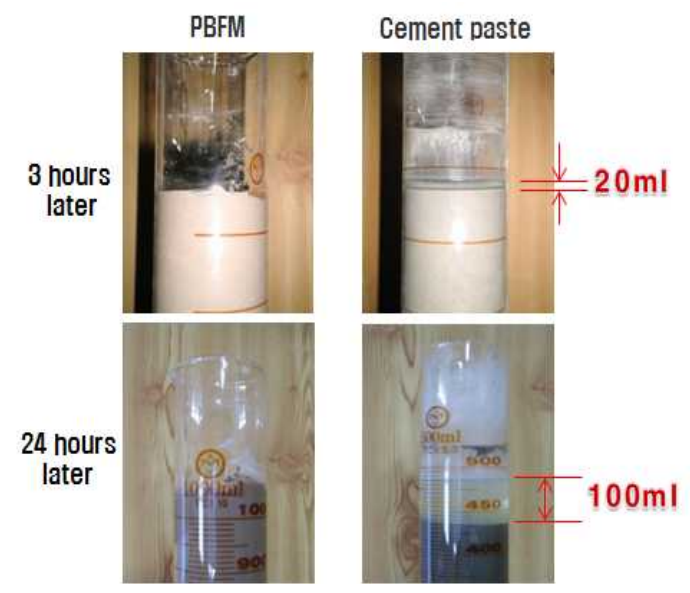

Figure 8. Segregation resistance test
In addition, unlike the percussion rotary drill technique, the pile backfilling method accompanies excavations larger than the diameter of the pile, and itis important to fill the void space between the wall and the surface of the pile. As illustrated in Figure 7, no shrinkage was found in PBEM, while shrinkage was found in cement paste due to bleeding. The shrinkage of cement paste is believed to cause a deterioration in the total friction by reducing the frictional surface between the excavated ground and the pile after the cement is cured.

\subsection{Compressive strength}

The compressive strength was measured using the 50 ton Universal Testing Machine (U.T.M). As illustrated in Figure 9, the compressive strength of PBFM was shown to be $1.97 \mathrm{MPa}$ on average, which was much lower than that of cement paste. However, the compressive strength of liquefied stabilized soil similar to PBFM was shown to be lower than $0.5 \mathrm{MPa}$ on average. PBFM was shown to have developed three times higher compressive strength compared to the maximum strength of 0.56MPa mentioned by Kantamasayuki (2004)[6].

A filling material can affect friction between the surface, filling material and the surrounding ground, as well as bond strength to some degree. However, since the strength of the filling material is higher than that of the surrounding ground, little improvement of friction is expected between the filling material and the surrounding ground. That is, it is believed that taking the role of filling into account, if the required strength of a filling material is stronger than that of the surrounding ground, the material can satisfactorily serve as a filling material. 


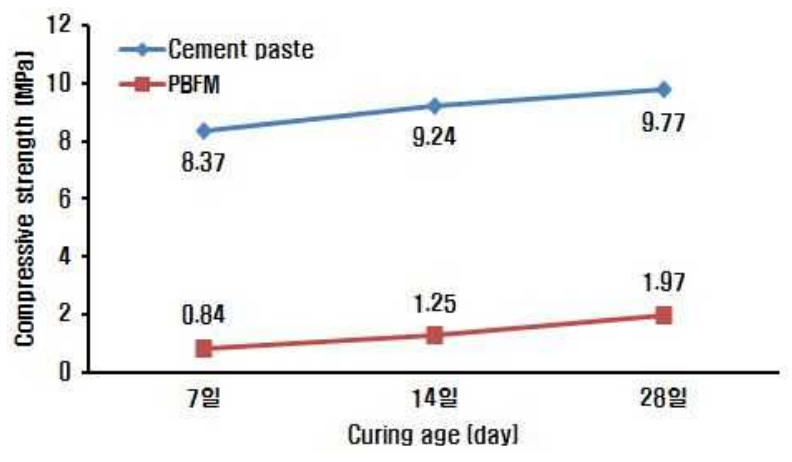

Figure 9. Segregation resistance test

\subsection{Bond strength}

The important thing in pile work is bond strength between the pile and filling material. If the bond strength is not sufficient, the pile and filling material behave independently, and it is hard for skin friction of the pile to be exerted. As shown in Figure 10, the bond strength of PBFM developed to be $25 \%$ higher than that of cement paste, while the compressive strength of PBMF developed to be lower than that of cement paste. PBFM is expected to behave in one unit with the PHC pile, unlike the cement paste that is in wide use as a filling material.

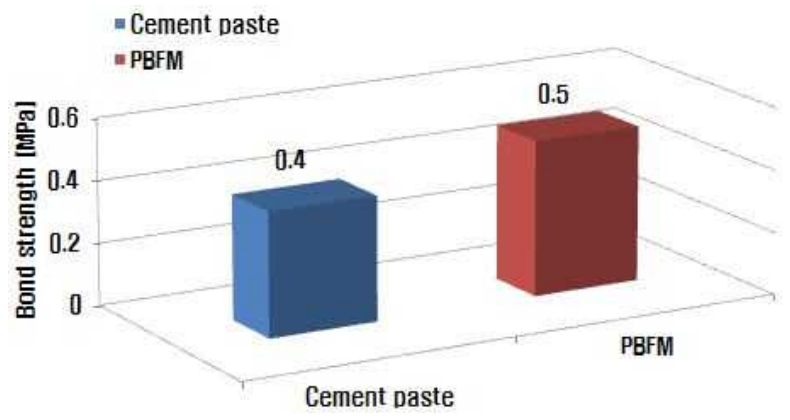

Figure 10. Bond strength results

\subsection{Direct shear test}

The direct shear test is generally used to analyze the characteristics of contact applied to diverse materials as well as the bond strength on the contact area between geosynthetics and soil, but Ray et al.[7] used the direct shear test method to measure the bond strength on the contact area between two types of concrete.

As illustrated in Figures 11 and 12, shear stress of PBFM was measured to be $69.5 \mathrm{~kg} / \mathrm{cm}^{2}$ at horizontal displacement of $1.5 \mathrm{~kg} / \mathrm{cm}^{2}$, which was 87\% the shear stress performance of cement paste $\left(79.7 \mathrm{~kg} / \mathrm{cm}^{2}\right)$. On the other hand, in the relation between vertical stress and maximum shear strength, both cement paste and PBFM are believed to be dependent on the horizontal displacement. In general, the shear stress of PBFM was shown to be lower than that of cement paste. But the difference in shear stress between the two was within $13 \%$ to the maximum. Since the shear stress is affected by the type and shear stress of the ground, the difference is not considered to be that great.

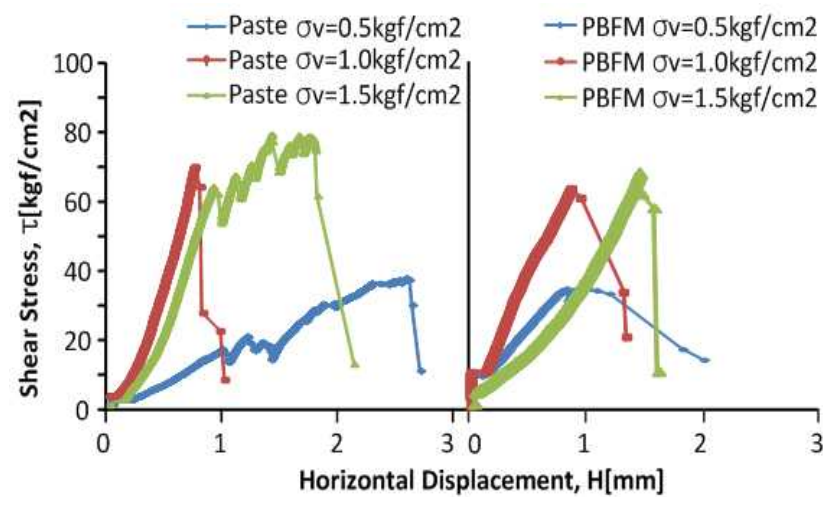

Figure 11. Direct shear test results

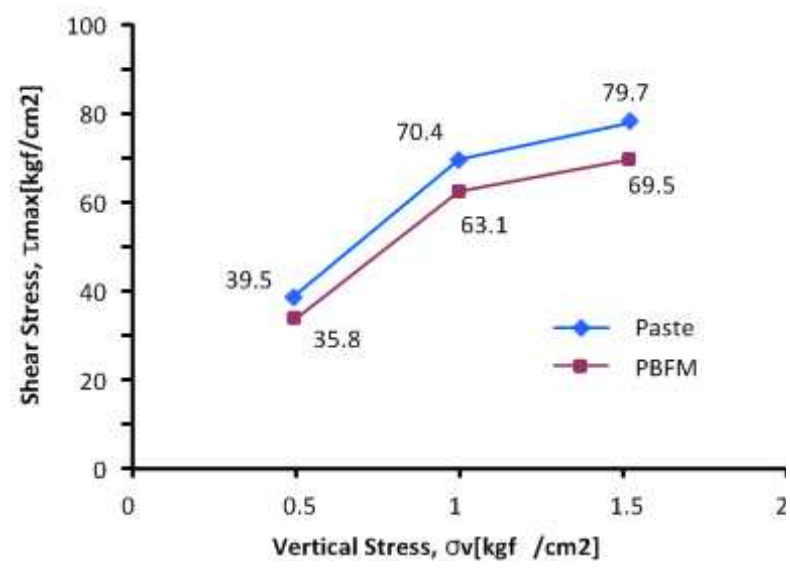

Figure 12. Influence of vertical stress on shear stress 


\subsection{Dynamic load test}

To conduct a dynamic load test, a pile was inserted into a drilled hole, either cement paste or PBFM was placed in the drilled hole, and the first strike was made using a hammer to measure the initial shear strength and skin friction. And the second strike was made at 7 days of curing to measure the shear strength and skin friction of the pile. A comparative analysis was performed, and the analysis results were indicated in Table 4 . The total shear strength of PHC pile filled with cement mortar was higher than that of PHC pile filled with PBFM. In addition, the skin friction of PHC filled with cement mortar was also higher than that of PHC pile filled with PBFM. However, the two specimens were tested at a construction site, but the construction site contained a lot of core stone in the ground. Total shear strength can be affected by the location of core stone, and slight consideration is needed for a simple comparison between the dynamic load test results shown in Table 4.

Table 4. Dynamic load tests results

\begin{tabular}{|c|c|c|c|c|c|}
\hline \multicolumn{2}{|c|}{$\begin{array}{c}\text { Type of } \\
\text { backfilling material }\end{array}$} & $\begin{array}{l}\text { Skin } \\
\text { friction } \\
\text { force } \\
\text { (ton) }\end{array}$ & $\begin{array}{c}\text { End } \\
\text { Bearing } \\
\text { Capacity } \\
\text { (ton) }\end{array}$ & $\begin{array}{l}\text { Total } \\
\text { load } \\
\text { capacity } \\
\text { (ton) }\end{array}$ & $\begin{array}{c}\text { Skin } \\
\text { friction } \\
\text { force } \\
/ \text { Total } \\
\text { load } \\
\text { capacity }\end{array}$ \\
\hline \multirow{2}{*}{ PBFM } & Early & 11.0 & 101.0 & 112.0 & 0.1 \\
\hline & Re-strike & 48.7 & 121.4 & 170.1 & 0.29 \\
\hline \multirow{2}{*}{$\begin{array}{l}\text { Cement } \\
\text { Paste }\end{array}$} & Early & 12.0 & 108.6 & 120.6 & 0.1 \\
\hline & Re-strike & 68.2 & 141.8 & 209.9 & 0.32 \\
\hline
\end{tabular}

To verify the applicability of PBFM as a filling material, other influencing factors were not considered, and to verify skin friction, the skin friction on total load capacity was considered as dimensionless. The results indicated that the skin friction on total load capacity was measured to be 0.1 in both specimens at the initial strike, but the skin friction on total load capacity was measured as
0.29 in PBFM at the second strike, which was $10 \%$ lower than cement paste. The performance of PBFM was slightly lower, but considering influencing factors from different angles, including the disposal cost of industrial waste and environmental destruction, and the site condition such as the selection of a bigger pile, it is expected that PBFM will be applied as a filling material.

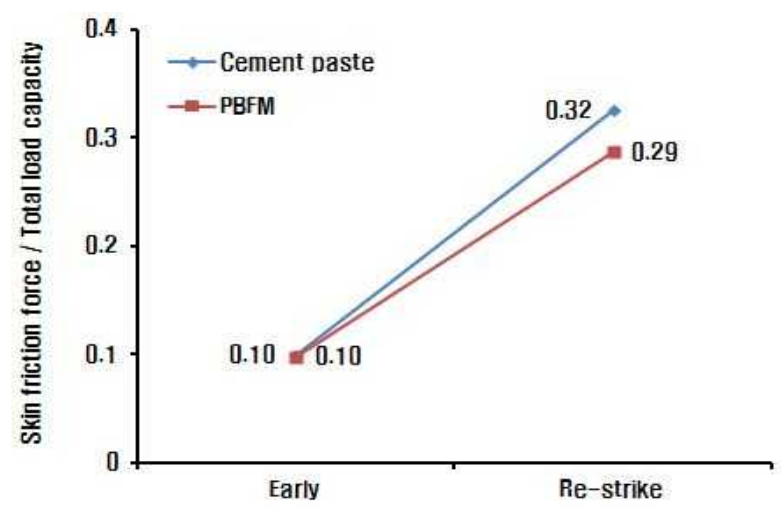

Figure 13. Skin friction force on total load capacity

\section{Conclusion}

The applicability of PBFM as a filling material was evaluated to resolve such problems as increased construction cost and environmental destruction arising from the use of cement paste for pile backfilling when PHC pile work is done at a construction site, as well as to recycle the in-site soil generated from pile drilling as a substitute for the cement paste.

1) In terms of fluidity, PBFM was found to satisfy the required fluidity, but material segregation was found in cement paste due to there being too much water, and for this reason it was impossible to conduct the fluidity evaluation.

2) Segregation resistance of PBFM was very high, and no shrinkage was found 24 hours after placement.

3) The compressive strength of PBFM was much 
lower than that of cement paste, but 3 times higher than the maximum strength of $0.56 \mathrm{MPa}$ required in Tokyo, Japan.

4) The bond strength of PBFM was 25\% higher than that of cement paste. But in shear stress test, the shear stress of PBFM was 13\% lower than that of cement paste to the maximum.

5) From the analysis after the second strike, it was found that the shear stress and skin friction of the pile filled with cement paste were higher than those of the pile filled with PBFM.

In conclusion, in terms of construct ability, PBFM is more advantageous in terms of segregation resistance and good fluidity, but disadvantageous in terms of bond strength and shear stress. Through the dynamic load tests, it was found that PBFM was also slightly worse in a structural aspect. However, the structural disadvantage can be supplemented by a technical method, and it is very effective to recycle the in-site soil as a construction material taking construction cost and the environmental aspect into account.

\section{References}

1. Kim BI, Wee SH, Lee SH, Kim YU. Strength Characteristics of Siol-Cement Mixed with Inorganic Solidification Liquid, Korea Society of Civil Engineers. 2003;23(3C):135-41.

2. Park JH, Lee KH, Jo JH, Kim SN. Deformation Characteristics of Underground Pipe with In-site Soil CLSM. Korea Geotechnical Society. 2004; 20(3):129-39.

3. Korea Land \& Housing Corporation. LH Construction Specifications 30535. Suwon (Korea): Land \& Housing Corporation; 2010.

4. ASTM Standards D6103, 2004, Standard Test Method for Flow Consistency of Controlled Low Strength Material (CLSM), ASTM International, West Conshohocken.

5. ASTM Standards C940-98a, 2003, Standard Test Method for Expansion and Bleeding of Freshly Mixed Grouts for Preplaced-Aggregate Concrete in the Laboratory, ASTM
International, West Conshohocken.

6. Kantamasayuki. Technolygies for high performance of Controlled low strength meterials. Tokoy (Japan): Kisotakumi; 2004. p. 57-60.

7. Ray I, Davalos JF, Luo S. Interface Evaluations of Overlay-Concrete Bi-Layer Composites by a Direct Shear Test Method. Cement and Concrete Composites. 2005;27(3): 339-47. 